\title{
Prevalence of diabetic retinopathy and visual impairment in patients with diabetes mellitus in Zambia through the implementation of a mobile diabetic retinopathy screening project in the Copperbelt province: a cross-sectional study
}

\author{
Adam D. Lewis ${ }^{1} \cdot$ Ruth E. Hogg ${ }^{2} \cdot$ Manju Chandran ${ }^{1} \cdot$ Lillian Musonda $^{3} \cdot$ Lorraine North $^{1} \cdot$ Usha Chakravarthy $^{2}$. \\ Sobha Sivaprasad ${ }^{4} \cdot$ Geeta Menon $^{1}$
}

Received: 3 September 2017 / Revised: 13 January 2018 / Accepted: 30 January 2018 / Published online: 5 March 2018

(c) The Royal College of Ophthalmologists 2018

\begin{abstract}
Aims A paucity of literature exists on prevalence of diabetic retinopathy (DR) in sub-Saharan Africa. We aim to estimate the prevalence of DR and visual impairment in Zambia's Copperbelt province through a cross-sectional study.

Methods All patients with a diagnosis of diabetes mellitus attending a DR screening programme were eligible to participate. Fundus photographs were graded in accordance with the DR grading system used in the UK National Health service (NHS). Visual impairment data were collected from visual acuity measurements recorded using Snellen chart.

Results A total of 2689 patients were screened and of these, 2153 patients had a least one eye of gradable quality for analysis. Fifty-five per cent (1190/2153) of patients were male. Mean age was 56 (SD 11). Fifty-two per cent (1113/2153) showed evidence of diabetic retinopathy (DR). Thirty-six per cent of patients graded (779/2153) had sight threatening DR. Proliferative DR was found in 7\% (14/208) of type 1 diabetics compared to 5\% (42/921) type 2 diabetics $(p=<0.001)$. Duration of diabetes, random blood glucose, systolic and diastolic BP, and use of insulin and oral hypoglycaemics were strongly associated with DR in univariate analysis. The associations of increased systolic BP, random blood glucose, duration of diabetes and insulin use with DR were maintained in multivariate analysis.

Conclusion We observed a high prevalence of sight threatening DR which is close to the upper range of estimates that currently exist on DR. This study represents further evidence of global health inequality and the scale of the epidemic which sub-Saharan African countries now face.
\end{abstract}

\section{Introduction}

Zambia is a landlocked country in south, central Africa with a rapidly growing population of 13.2 million. It is a middleincome economy reliant predominantly on copper, farming and tourism. Economic growth over the last decade has seen

Adam D. Lewis

adamlewis@ doctors.org.uk

1 Department of Ophthalmology, Frimley Park Hospital, Frimley, UK

2 Centre for Public Health, Queen's University of Belfast, Belfast, UK

3 Kitwe Central Hospital, Kitwe, Zambia

4 Moorfields Eye Hospital, London, UK some improvement in medical facilities and a fall in infective diseases. However, the new prosperity has brought with it a rise in non-communicable diseases, including diabetes mellitus (DM) and cardiovascular disease. In this context, it is notable that there has been a dramatic increase in levels of obesity from 12 to $19 \%$ [1] of the population in just 5 years, partly explaining the rising incidence of DM. Once thought to be a rare disease on the African continent, the prevalence of diabetes has been shown be on the rise in sub-Saharan urban populations [2]. The International Diabetes Federation [3] estimates a projected growth of prevalence of diabetes in sub-Saharan Africa from 12.1 million in 2010 to 23.9 million in 2030. Urbanisation and rising levels of obesity are thought to be major contributing factors to what is increasingly described as a growing epidemic. Non-communicable diseases are listed as a priority in Zambia's national health strategic plan (NHSP) [4]. DM 
was highlighted as having the poorest diagnostic facilities and lowest levels of access to treatment of all noncommunicable diseases. This strategic plan supports the aims of Vision 2020: the right to sight [5], and seeks to improve diagnosis and treatment of preventable blindness.

Currently, there are no published reports on the prevalence of diabetic retinopathy (DR) in Zambia and data on DR and its associated risk factors throughout sub-Saharan Africa is scarce. DR is a leading cause of blindness and visual impairment in the working-age population in the developed world $[6,7]$.

We initiated a screening programme for DR in the predominantly urban population in the Copperbelt province of Zambia. Prior to this intervention there was no diabetic eye screening programme in this part of the country. We exploited this on-going programme to estimate the prevalence of DR and to explore factors contributing to its development in this urban population in Zambia.

\section{Methods}

A cross-sectional prospective study of patients with a diagnosis of diabetes mellitus was carried out using a mobile screening unit in five urban centres within the Copperbelt province, Zambia. Diabetic patients were identified either through diabetic registers (Kitwe, Chililabombwe, Chingola and Ndola provinces) or through pharmacy registers (Luanshya and Mufulira provinces). All patients with a diagnosis of diabetes mellitus were made aware of screening. Patients were contacted via a public awareness programme using local billboard advertising and local radio or TV broadcasts and within local church congregations. A total of 3100 patients were eligible for screening, of which 2689 attended the mobile screening units between February and June 2012, representing an 87\% response rate. Of the 2689 who attended 2153 patients were eligible for the prospective study based on predefined eligibility criteria (below). Informed consent was obtained from each patient prior to data collection and screening. The research project was approved by Topical Diseases Research Centre (TDRC), Ndola, Republic of Zambia.

\section{Patient involvement}

No patients were involved in setting the research question or the outcome measures, nor were they involved in developing plans for design or implementation of the study. Patients were involved in recruitment through local publicity projects to encourage attendance at diabetic screening centres. No patients were asked to advise on interpretation or writing up of results. Results of the research will be disseminated to study participants and the wider patient community using information leaflets and hospital posters.

\section{Eligibility criteria}

All patients attending the DR screening programme were eligible to take part in the study. Where at least one eye was gradable (Table 1), the patient was included in analysis.

\section{Exclusion criteria}

Patients were excluded from the study where photographic images were missing. Where both eyes were ungradable (Table 1), patients were excluded from retinopathy grading.

\section{Study protocol}

The screening unit personnel consisted of a local ophthalmologist, nurses and trained technicians. Demographic and clinical details of those who attended the screening unit were collected by the screening unit personnel using a common structured case report form. The same form was used by all screening centres. Patients were surveyed regarding diabetic type, duration of diabetes and current treatment including medications for diabetes and cardiovascular disease. Data entry was performed at Kitwe central hospital using a customised database. Visual acuity was measured using Snellen charts. BMI was calculated using weight $(\mathrm{kg}) / \operatorname{height}^{2}(\mathrm{~m})$ and BP (one arm, in sitting position) were measured. Pharmacological mydriasis was achieved with tropicamide (1\%) drops. Each patient underwent dilated colour fundus photography using the Digital Retinopathy System (DRS, CentreVue, CA, USA) fundus camera. Images were captured by trained technicians. Two non-stereo fundus photographic fields $\left(45 \times 40^{\circ}\right)$ were captured for each eye. One field included the macula and arcades, the second field included the nasal fundus centred on the optic disc.

\section{Fundus grading}

Following fundus image capture, trained personnel employed at the Kitwe Central Hospital from both nursing and non-medical backgrounds undertook grading of the images on site at the time of photography. Graders were trained at a series of workshops organised by visiting ophthalmologists from Frimley Park Hospital (FPH), UK. Grading skills were taught over a series of week-long visits which took place both in Kitwe, Zambia and a visit to FPH. Images were graded in accordance with the DR grading system used in the UK National Health service (NHS) screening programme [8]. 
Table 1 Diabetic retinopathy (DR) grading protocol

\begin{tabular}{|c|c|c|}
\hline Retinopathy & & Grading features \\
\hline R0 & No visible retinopathy & No retinopathy features \\
\hline R1 & Background & $\begin{array}{l}\text { Any Microaneurysm(s) (MA) } \\
\text { Any Haemorrhage(s) } \\
\text { Any exudates }\end{array}$ \\
\hline R2 & Preproliferative & $\begin{array}{l}\text { Venous beading } \\
\text { Venous loop or reduplication } \\
\text { Intraretinal microvascular abnormality (IRMA) } \\
\text { Multiple deep, round or blot haemorrhages }\end{array}$ \\
\hline R3 & Proliferative & $\begin{array}{l}\text { New vessels on disc (NVD) } \\
\text { New vessels elsewhere (NVE) } \\
\text { Pre-retinal or vitreous haemorrhage }\end{array}$ \\
\hline $\begin{array}{l}\text { Retinopathy ungradable } \\
\text { (U) }\end{array}$ & & $\begin{array}{l}\text { Clarity of vessels insufficient to perform useful } \\
\text { analysis } \\
\text { Macula or disc not centred in field of view }\end{array}$ \\
\hline \multicolumn{3}{|l|}{ Maculopathy } \\
\hline M0 & No visible maculopathy & No maculopathy features \\
\hline M1 & Maculopathy & $\begin{array}{l}\text { Exudate within } 1 \text { disc diameter (DD) of the fovea } \\
\text { centre } \\
\text { Circinate or group of exudates within the macula } \\
\text { Any MA or haemorrhage within } 1 \mathrm{DD} \text { of fovea } \\
\text { centre associated with BCVA } \leq 6 / 12\end{array}$ \\
\hline Maculopathy ungradable & & Small vessels of macula not clearly visible \\
\hline
\end{tabular}

Table 2 WHO grading of better eye in patients with diabetes $(n=$ 2153)

\begin{tabular}{lcll}
\hline Snellen visual acuity in metres (feet) & $n$ & $\%$ & $95 \%$ CI \\
\hline $6 / 6(20 / 20)$ & 625 & 29.0 & $27.1-30.9$ \\
$6 / 9(20 / 30)$ & 487 & 22.6 & $20.9-24.4$ \\
$6 / 12(20 / 40)$ & 401 & 18.6 & $17.0-20.3$ \\
$6 / 18(20 / 60)$ & 271 & 12.6 & $11.2-14.0$ \\
$6 / 24(20 / 80)$ & 153 & 7.1 & $6.0-8.2$ \\
$6 / 36(20 / 120)$ & 119 & 5.5 & $4.6-6.5$ \\
$6 / 60(20 / 200)$ & 66 & 3.1 & $2.3-3.8$ \\
$3 / 60(20 / 400)$ & 15 & 0.7 & $0.3-1.0$ \\
Hand movements $(\mathrm{HM})$ & 7 & 0.3 & $0.1-0.6$ \\
Perception of light (PL) & 4 & 0.2 & $0.0-0.4$ \\
No perception of light $(\mathrm{NPL})$ & 5 & 0.2 & $0.0-0.4$ \\
Normal vision $(6 / 6-6 / 18)$ & 1784 & 82.9 & $81.3-84.5$ \\
Visual impairment $(\leq 6 / 18-6 / 60)$ & 338 & 15.7 & $14.2-17.2$ \\
Severely visually impaired $(\leq 6 / 60-N P L)$ & 31 & 1.4 & $0.9-1.9$ \\
\hline
\end{tabular}

Secondary grading, for the purposes of statistical evaluation used in this paper, was undertaken at the reading centre in Queen's University of Belfast by an ophthalmologist from FPH who spent a 6-week period of training in DR grading prior to embarking on the grading exercise. Each eye was graded separately for retinopathy and maculopathy. Image quality was classified as gradable or ungradable according to the features in Table 1. Sight threatening DR was defined as diabetic retinopathy of R2 or worse or the presence of maculopathy (M1). Although each eye was graded separately, patients were classified for statistical purposes according to the grade of the worse eye. In the reading centre, additional quality assurance was conducted with $10 \%$ of images re-graded by a professional image grader. Agreement between the FPH grader and the professional grader was $82 \%$, based on exact agreement for all images.

\section{Visual impairment}

Visual acuity was measured at the time of screening using a Snellen chart at 6 metres, spectacles where appropriate, and pin hole. Patients were classified according to WHO definitions of visual impairment (Table 2). This table presents the visual acuity of all diabetic patients screened, including those patients whose photographs could not be graded due to cataract and other ocular media opacities. 


\section{Statistical analysis}

Statistical analysis was performed using the Statistical Package for the Social Sciences, Windows version 21 (SPSS, Inc., Armonk, NY). Categorical demographic and clinical data were compared using Pearson's $\chi^{2}$-test. Continuous variables were using the Independent samples t-test. Generalised logistic regression was used initially to assess each factor individually with the presence or absence of diabetic retinopathy and also for building the multivariate final model. A backward stepwise technique was used to determine the final multivariate model. Type of diabetes was not assessed within the regression model due to the large number of missing variables $(>50 \%) . P$ values $<0.05$ were considered statistically significant.

\section{Results}

\section{Demographic details}

A total of 2689 diabetic patients were screened. Of these, 2153 patients had at least one eye of gradable quality for statistical analysis. Three hundred and ninety-five patients were excluded from grading analysis as they had ungradable images in both eyes. One hundred and forty-one patients were excluded due to missing photographs. All patients were of black African ethnicity.

The clinical characteristics of the patients included in statistical analysis were: type 1 diabetes 9.7\% (208/2153), type 2 diabetes $42.8 \%(921 / 2153)$ and diabetes unspecified $47.6 \%$ (1024/2153). Fifty-five per cent (1190/2153) of patients were male. Mean age was 56 (SD 11), median age was 56 and range was 77. Mean reported duration of diagnosed diabetes was 7 years (SD 6), median was 5 years and range was 50 years. Forty-eight per cent (1034/2153) of patients had a family history of diabetes. Of the remaining patients, 853 reported no family history of diabetes and 266 were unsure.

Seventy-eight per cent (163/208) of type 1 diabetics were on insulin. Eight-five per cent of type 2 diabetics (783/921) were on oral hypoglycaemics, 14\% (127/921) were diet controlled and $1 \%(11 / 921)$ were on insulin.

\section{Diabetic retinopathy}

The prevalence of DR grades based on the worst affected eye on second grading in Queen's University Read Centre is shown in Table 3. Fifty-two per cent (1113/2153) of all diabetic patients (type 1, type 2 and type unspecified) showed evidence of DR. Thirty-six per cent of patients graded (779/2153) had sight threatening DR. Six per cent $(128 / 2153)$ of all patients were graded as having proliferative DR. Proliferative DR was found in 7\% type 1 diabetics $(14 / 208)$ compared to $5 \%(42 / 921)$ of type 2 diabetics $(p=<0.001)$. Prevalence of sight threatening DR was $57 \%(118 / 208)$ in type 1 diabetics compared to $44 \%$ (402/921) of type $2(p=<0.001)$. Of those patients graded with retinopathy, 62\% (695/1113) also had photographic evidence of maculopathy (M1). Maculopathy was found in $54 \%(112 / 208)$ of type 1 diabetics compared to $41 \%$ (337/ $921)$ of type 2 diabetics $(p=<0.001)$.

Risk factors associated with DR are shown in Table 4. Duration of diabetes, random blood glucose, hypertension (JNC grade 2: systolic $>160$ or diastolic $>100$ ) and use of insulin and oral hypoglycaemics were strongly associated with DR in univariate analysis. The association of increased systolic BP, random blood glucose, duration of diabetes and insulin use with DR was maintained in multivariate analysis.

\section{Visual acuity}

Distribution of Snellen visual acuities according to better eye in all patients with DM is shown in Table 2. According to WHO definitions 1784 patients $(82.9 \%$ (81.3-84.5\%)) had normal vision, 338 patients $(15.7 \%(14.2-17.2 \%))$ were visually impaired and 31 patients $(1.4 \%(0.9-1.9 \%))$ were severely sight impaired. Table 5 presents retinal grading and visual acuity according to the worse eye.

\section{Discussion}

We report rates of DR in patients attending a novel screening programme in the Copperbelt province, Zambia. This study provides baseline data on prevalence of DR in a diabetic population in Zambia and its associated risk factors. To the best of our knowledge there have been no previously published data on DR prevalence in Zambia. Previous studies of DR in sub-Saharan Africa have shown a high degree of variability in DR, with estimates ranging from 7\% [9] to 63\% [10]. Type 2 diabetes accounts for over $90 \%$ of DM in sub-Saharan Africa [11] with type 1 diabetes predominantly affecting populations of European ancestry [12].

A large study of patients with Type 2 diabetes in the UK reported a higher prevalence of DR in patients of African descent compared to white patients living in the UK [13]. Known as the DRIVE UK study, this study found a prevalence of $52 \%$ in the black community compared to $38 \%$ in white Europeans. The present study found similar rates of DR in Zambia in just under 52\% of persons with DM. What was striking, however, was the very high levels sight threatening DR which was three-fold higher than that reported in the DRIVE study. Epidemiological studies on 
Table 3 Patient demographics and prevalence of retinopathy according to worse eye in patients with type 1 and type 2 diabetes

\begin{tabular}{|c|c|c|c|c|c|c|c|}
\hline & $\begin{array}{c}\text { All, } \\
n=2153\end{array}$ & $\begin{array}{l}\text { Type } 1 \\
n=208\end{array}$ & $\begin{array}{l}\text { Type } 2 \\
n=921\end{array}$ & $p$ value & $\begin{array}{l}\text { No retinopathy, } \\
n=1040\end{array}$ & $\begin{array}{l}\text { Any retinopathy, } \\
\quad n=1113\end{array}$ & $p$ value \\
\hline Age, mean (SD) & $56(11)$ & $52(13)$ & $56(10)$ & $<0.001$ & $55(12)$ & $56(10)$ & 0.078 \\
\hline Gender $n(\%)$, males & $1190(55)$ & $109(52)$ & $504(55)$ & 0.526 & $561(54)$ & $629(57)$ & 0.230 \\
\hline BMI, mean (SD) & $28(6)$ & $28(3)$ & $27(6)$ & 0.411 & $28(6)$ & $27(6)$ & 0.042 \\
\hline $\begin{array}{l}\text { Systolic blood pressure, mean } \\
\text { (SD) }\end{array}$ & $148(30)$ & $143(28)$ & $148(29)$ & 0.022 & $114(28)$ & $151(30)$ & $<0.001$ \\
\hline $\begin{array}{l}\text { Diastolic blood pressure, mean } \\
\text { (SD) }\end{array}$ & $88(14)$ & $86(14)$ & $87(15)$ & 0.068 & $87(14)$ & $89(14)$ & 0.001 \\
\hline \multicolumn{8}{|l|}{ Cardiovascular Medication } \\
\hline No $(\%)$ & $1638(76)$ & $111(53)$ & $513(56)$ & $<0.001$ & $818(78)$ & $820(74)$ & 0.007 \\
\hline Yes & $515(24)$ & $97(47)$ & $408(44)$ & & $222(21)$ & $293(26)$ & \\
\hline \multicolumn{8}{|l|}{ Hypertension statusn (\%) } \\
\hline Normal $(<120$ and $<80)$ & $224(11)$ & $33(16)$ & $91(10)$ & 0.299 & $129(12)$ & $115(10)$ & 0.002 \\
\hline $\begin{array}{l}\text { Pre-hypertension (120-139 or } \\
80-89)\end{array}$ & $553(26)$ & $57(27)$ & $338(37)$ & & $295(28)$ & $258(23)$ & \\
\hline $\begin{array}{l}\text { Hypertension } 1 \text { (140-159 or } \\
90-99)\end{array}$ & $552(26)$ & $47(23)$ & $235(26)$ & & $264(25)$ & $288(26)$ & \\
\hline Hypertension $2(\geq 160$ or $\geq 100)$ & $783(36)$ & $71(34)$ & $245(27)$ & & $341(33)$ & $442(40)$ & \\
\hline Missing & $21(1)$ & $0(0)$ & $12(1)$ & & $11(1)$ & $10(1)$ & \\
\hline $\begin{array}{l}\text { Random blood glucose, mean } \\
\text { (SD) }\end{array}$ & $11(5)$ & $10(5)$ & $10(4)$ & 0.908 & $10(5)$ & $11(5)$ & $<0.001$ \\
\hline $\begin{array}{l}\text { Duration of diabetes (years), } \\
\text { mean (SD) }\end{array}$ & $7(6)$ & $9(8)$ & $6(6)$ & $<0.001$ & $5(5)$ & $8(7)$ & $<0.001$ \\
\hline \multicolumn{8}{|l|}{ Diabetes typen $(\%)$} \\
\hline Type 1 & $208(10)$ & NA & NA & NA & $79(8)$ & $129(12)$ & \\
\hline Type 2 & $921(43)$ & & & & $440(42)$ & $481(43)$ & 0.003 \\
\hline Unspecified & $1024(48)$ & & & & $521(50)$ & $503(45)$ & \\
\hline \multicolumn{8}{|l|}{ Family history of diabetesn (\%) } \\
\hline No & $853(40)$ & $61(29)$ & $363(39)$ & 0.002 & $425(41)$ & $428(39)$ & 0.077 \\
\hline Yes & $1034(48)$ & $123(59)$ & $435(47)$ & & $473(46)$ & $561(50)$ & \\
\hline Unknown & $266(12)$ & $24(12)$ & $123(13)$ & & $142(14)$ & $124(11$ & \\
\hline \multicolumn{8}{|l|}{ Treatment } \\
\hline Diet controlled & 304 (14) & $5(4)$ & $127(14)$ & $<0.001$ & $188(18)$ & $116(10)$ & $<0.001$ \\
\hline Hypoglycaemics & $1494(69)$ & $36(17)$ & $783(85)$ & & $727(70)$ & 767(69) & \\
\hline Insulin & $355(17)$ & $163(78)$ & $11(1)$ & & $125(12)$ & $230(21)$ & \\
\hline \multicolumn{8}{|l|}{ Sight threatening $D R$} \\
\hline No & $1375(64)$ & $90(43)$ & $519(56)$ & $<0.001$ & $1040(100)$ & $335(30)$ & NA \\
\hline Yes & $778(36)$ & $118(57)$ & $402(44)$ & & $0(0)$ & $778(70)$ & \\
\hline \multicolumn{8}{|l|}{ Retinopathy Stage $n(\%)$} \\
\hline None & $1041(48)$ & $80(39)$ & $440(48)$ & & $1040(100)$ & $0(0)$ & NA \\
\hline $\mathrm{R} 1$ & $558(26)$ & $53(26)$ & $256(28)$ & $<0.001$ & $0(0)$ & $559(50)$ & \\
\hline R2 & $426(20)$ & $61(29)$ & $183(20)$ & & $0(0)$ & $426(38)$ & \\
\hline R3 & $128(6)$ & $14(7)$ & $42(5)$ & & $0(0)$ & $128(12)$ & \\
\hline \multicolumn{8}{|l|}{ Maculopathy Stage $n(\%)$} \\
\hline M0 & $1458(68)$ & $96(46)$ & $544(59)$ & $<0.001$ & $1040(100)$ & $418(38)$ & NA \\
\hline M1 & 695 (32) & $112(54)$ & 377 (41) & & $0(0)$ & $695(62)$ & \\
\hline $\begin{array}{l}\text { Visual acuity worst eye, mean } \\
\text { (SD) }\end{array}$ & $0.37(0.38)$ & $0.37(0.32)$ & $0.37(0.33)$ & 0.935 & $0.37(0.40)$ & $0.43(0.35)$ & 0.002 \\
\hline
\end{tabular}

$P<0.05$ are marked in bold 
Table 4 Univariate and multivariate logistic regression showing the risk factors associated with the development of diabetic retinopathy in those with diabetes mellitus

\begin{tabular}{|c|c|c|c|c|c|c|}
\hline & \multirow{2}{*}{$\begin{array}{l}\text { Univariate } \\
\text { regression } \\
\text { OR }\end{array}$} & \multicolumn{5}{|c|}{ Multivariate regression } \\
\hline & & $95 \% \mathrm{CI}$ & $p$ value & OR & $95 \% \mathrm{CI}$ & $p$ value \\
\hline Age & 1.01 & $1.00-1.02$ & 0.078 & 1.00 & $0.99-1.01$ & 0.681 \\
\hline Sex: male vs. female & 0.90 & $0.76-1.07$ & 0.230 & 0.85 & $0.70-1.04$ & 0.100 \\
\hline Systolic BP & 1.01 & $1.00-1.01$ & $<0.001$ & 1.01 & $1.00-1.01$ & $<0.001$ \\
\hline Diastolic BP & 1.01 & $1.00-1.01$ & 0.001 & & & \\
\hline \multicolumn{7}{|l|}{ JNC 7 hypertension classification } \\
\hline Normal $(<120$ and $<80)$ & 1.0 & & & & & \\
\hline $\begin{array}{l}\text { Pre-hypertension (120-139 or } \\
80-89)\end{array}$ & 0.98 & $0.73-1.32$ & 0.901 & & & \\
\hline Hypertension 1 (140-159 or 90-99) & 1.22 & $0.91-1.70$ & 0.190 & & & \\
\hline Hypertension 2 ( $\geq 160$ or $\geq 100$ ) & 1.45 & $1.09-1.94$ & 0.011 & & & \\
\hline Cardiovascular Medication use & 1.32 & $1.08-1.61$ & $<0.001$ & & & \\
\hline Random blood glucose & 1.05 & $1.03-1.07$ & $<0.001$ & 1.05 & $1.02-1.07$ & $<0.001$ \\
\hline Body mass index (BMI) & 0.99 & $0.97-0.99$ & 0.043 & & & \\
\hline Duration of diabetes (years) & 1.11 & $1.10-1.13$ & $<0.001$ & 1.11 & $1.08-1.13$ & $<0.001$ \\
\hline Family history of diabetes & 1.18 & $0.98-1.41$ & 0.077 & & & \\
\hline \multicolumn{7}{|l|}{ Treatment } \\
\hline Diet-controlled & 1.43 & $0.88-2.31$ & 0.153 & 1.45 & $0.83-2.55$ & 0.196 \\
\hline Hypoglycaemics & 2.13 & $1.43-3.19$ & $<0.001$ & 1.44 & $0.90-2.31$ & 0.126 \\
\hline Insulin & 3.73 & $2.39-5.82$ & $<0.001$ & 2.08 & $1.24-3.51$ & 0.006 \\
\hline
\end{tabular}

$P<0.05$ are marked in bold. Multivariate regression, final model formed from those variables that remaining statistically significant plus age and sex

Table 5 Retinal grading and visual acuity according to worse eye $(n$ $=2153$ )

\begin{tabular}{ll}
\hline Retinal status (worse eye) $n(\%)$ & $\begin{array}{l}\text { Visual acuity (LogMAR), } \\
\text { mean (SD) }\end{array}$
\end{tabular}

\begin{tabular}{lll}
\hline Retinopathy & & \\
0 & $1040(48 \%)$ & $0.37(0.40)$ \\
1 & $558(26 \%)$ & $0.35(0.30)$ \\
2 & $426(20 \%)$ & $0.48(0.35)$ \\
3 & $129(6 \%)$ & $0.58(0.47)$ \\
Maculopathy & & \\
0 & $1458(68 \%)$ & $0.34(0.38)$ \\
1 & $695(32 \%)$ & $0.52(0.34)$ \\
Sight threatening DR & & \\
0 & 1375 & $0.37(0.38)$ \\
1 & 778 & $0.45(0.37)$ \\
\hline
\end{tabular}

DR and its associated risk factors have overwhelmingly been carried out on white Caucasian populations. In a pooled analysis of 35 studies the overall prevalence of any DR was $34.6 \%$ [14]. On limiting the analysis to sight threatening DR only, the prevalence was $10.2 \%$. Of the 22,896 individuals, the 35 studies analysed only $9 \%$ were of
African descent. Ethnicity has, however, been shown to be a complex, independent risk factor [14] and the few studies that have examined the prevalence of type $1 \mathrm{DR}$ in black populations suggest that the clinical characteristics of patients in sub-Saharan Africa differ considerably from European cohorts. Firstly, the age of onset has been found to be later [15] and secondly insulinopenia more severe [16, 17]. In another study which compared black Africans with Indians, DR was reported in $69 \%$ of blacks vs. $60 \%$ of Indians. Black Africans were found to have an earlier onset of retinopathy from time of diagnosis and were also found to be more prone to hypertension than Indians [18].

In the present study, not only was the overall prevalence of sight threatening DR of $36 \%$ considerably higher than in Western populations but in addition this rose to $57 \%$ when we restricted the findings to persons with type 1 diabetes. This figure is even higher than that previously reported in sub-Saharan Africa [19, 20]. The increased frequency of sight threatening DR is likely to be multifactorial and there are a number of possible explanations. First, our cohort was drawn from a pool of persons with a history of diabetes and likely had a longer duration of this condition. Second, they also had a higher mean random blood glucose and uncontrolled hypertension than 
previous sub-Saharan studies $[20,21]$. Third, there was inadequate access to treatment with only $78 \%$ of patients with a diagnosis of type 1 diabetes reporting insulin use and this fell to $1 \%$ in those with type 2 diabetes. Fourth, uncontrolled hypertension (>140 systolic or 90 diastolic) was found in $62 \%(1335 / 2153)$ of our cohort. Fifth, there was variation in methodology, specifically patient selection and grading technique used. Rates of sight threatening DR and maculopathy tend to be higher in photography based studies [21] when compared to ophthalmoscopy studies $[22,23]$. Exclusive use of photographic grading could therefore account for the increased prevalence of sight threatening DR and maculopathy in our study. On the other hand, for PDR our data are similar to previously reported prevalence in other studies of sub-Saharan populations $[19,20]$ and worldwide data $[12,14]$.

The prevalence of type 2 diabetes in sub-Saharan Africa has increased with urbanisation and a move towards a more westernised diet. Rising levels of obesity and a move towards an increasingly sedentary lifestyle have been hypothesised [11, 24, 25] as possible causal factors in subSaharan Africa. Despite the role of obesity as a causal factor in DM we did not observe an association for a high BMI with DR. Our data are consistent with a small crosssectional study by Glover et al. [19] which reported prevalence of DR and associated risk factors in a diabetic cohort in neighbouring Malawi and which found no association between BMI and DR.

\section{Limitations of this study}

Our study was limited to a population of persons known to have diabetes. However, undiagnosed diabetes in subSaharan Africa is considerably larger and thus it is likely that we are underestimating the burden of DR in the community. Our findings imply that socio-economic status, lack of access to primary care and subsequently poor glycaemic and hypertensive control are important factors and that these can lead to late presentation and irreversible vision loss.

Much of the demographic data was collected by nurses and trained non-medical technicians using each patient's self-reported medical history and notes, where available. In cases where it was not possible to confirm diabetic type, we categorised the patient as 'diabetes unspecified' so as not to bias the statistical results of the study.

Diabetic retinopathy screening was carried out using two non-stereo fundal photographic images. This is in line with other international screening programmes, including the UK. Due to the limited resources in the Zambian healthcare system, the use of optical coherence tomography (OCT) was not employed.

Further research is needed to confirm these findings in larger numbers. In sub-Saharan Africa diabetes care competes for resources with other diseases such as HIV and malaria. This research highlights the need for policymakers to direct health-care resources to expand the diabetic screening project to the whole country in an attempt to halt the burden of DR on patients and the community as a whole.

\section{Conclusion}

This study is one of very few studies estimating prevalence of diabetic retinopathy in sub-Saharan Africa, and the first in Zambia. We observed a high prevalence of sight threatening DR which is close to the higher end of the range of estimates that currently exist on DR. This study represents further evidence of global health inequality and the scale of the epidemic which sub-Saharan African countries now face.

\section{Summary}

\section{What was known before}

- The prevalence of type 2 diabetes in sub-Saharan Africa has increased with urbanisation and a move towards a more westernised diet.

\section{What this study adds}

- This study is one of very few studies estimating prevalence of diabetic retinopathy in sub-Saharan Africa, and the first in Zambia.

- The prevalence of diabetic retinopathy in sub-Saharan Africa may be higher than previously thought.

Acknowledgements Staff of Frimley Hospital, England: Andrew Elliott, Thomas Poole, Brendan McIlhargey and Deana Robson. Staff and patients of Kitwe Central Hospital. Staff at the Reading Centre, Queen's University of Belfast; with particular thanks to Barbra Hamill. Ministry of Health, Republic of Zambia. National Eye Coordinator, Republic of Zambia: Dr Mulenga Muma. Vision 2020: Marcia Zondervan and Claire Walker.

Funding Tropical Health and Education Trust (THET) provided a grant to carry out the research project. CBM Christian Blind Mission (CBM) provided funding for the mobile fundus camera. Screening project was sponsored by Kitwe Central Hospital, Republic of Zambia. The funders had no direct involvement with the scientific aspects of the study.

Author contributions G.M., S.S. and M.C. conceived the study. G. M., M.C. and L.N. wrote the study protocol. L.N. and L.M. helped in screener technician training and data collection. R.H. and A.L. did the statistical analysis and A.L. wrote the first draft of the article. A.L., R.H., U.C., S.S. and G.M. made substantial contributions to interpretation of results and revision of the manuscript. G.M. is guarantor. 


\section{Compliance with ethical standards}

Conflict of interest The authors declare that they have no conflict of interest.

Ethics approval Ethics approval was obtained from Topical Diseases Research Centre (TDRC), Ndola, Republic of Zambia. ID No TDRC/ $\mathrm{ERC} / 3007 / 50 / 13$. All participants gave informed consent before taking part.

\section{References}

1. Central Statistical Office (CSO) [Zambia], Ministry of Health $(\mathrm{MOH})$ [Zambia], and ICF International Zambia Demographic and Health Survey 2013-14. Rockville, Maryland, USA: Central Statistical Office, Ministry of Health, and ICF International; 2014.

2. Hall V, Thomsen RW, Henriksen O, Lohse N Diabetes in sub Saharan Africa 1999-2011: epidemiology and public health implications. a systematic review. BMC Public Health. 2011;11:564.

3. Sicree R, Shaw J Zimmet: The Global Burden: Diabetes and Impaired Glucose Tolerance. Diabetes Atlas (4th Edition). Brussels (Belgium): International Diabetes Federation; 2009.

4. Ministry of Health, Republic of Zambia. National Health Strategic Plan 2011-2015. http://www.internationalhealthpartnership.net/ fileadmin/uploads/ihp/Documents/Country_Pages/Zambia/Za mbiaNHSP2011 to2015final..pdf.

5. Pizzarello L, Abiose A, Ffytche T, et al. VISION 2020: the right to sight: a global initiative to eliminate avoidable blindness. Arch Ophthalmol. 2004;122:615-20.

6. Congdon NG, Friedman DS, Lietman T Important causes of visual impairment in the world today. JAMA. 2003;290:2057-60.

7. Fong DS, Aiello L, Gardner TW, King GL, Blankenship G, Cavallerano JD, et al. Retinopathy in diabetes. Diabetes Care. 2004;27:84-87. suppl 1

8. Peto T, Tadros C Screening for diabetic retinopathy and diabetic macular edema in the United Kingdom. Curr Diab Rep. 2012;12:338-45.

9. Mwendwa F, Otieno C, Kayima J, Amayo E, Otieno P Risk factor profile and the occurrence of microvascular complications in short term type 2 diabetes mellitus at Kenyatta National Hospital, Nairobi. East Afr Med J. 2006;82:S163-72.

10. Mash B, Powell D, du Plessis F, Van Vuuren U, Michalowska M, Levitt N Screening for diabetic retinopathy in primary care with a mobile fundal camera-evaluation of a South African pilot. S Afr Med J. 2008;97:1284-8.
11. Levitt NS Diabetes in Africa: epidemiology, management and healthcare challenges. Heart. 2008;94:1376-82.

12. Sivaprasad S, Gupta B, Crosby-Nwaobi R, Evans J Prevalence of diabetic retinopathy in various ethnic groups: a worldwide perspective. Surv Ophthalmol. 2012;57:347-70.

13. Sivaprasad S, Gupta B, Gulliford MC, Dodhia H, Mann S, Nagi D, Evans J Ethnic variation in the prevalence of visual impairment in people attending diabetic retinopathy screening in the United Kingdom (DRIVE UK). PLoS ONE. 2012;7:e39608.

14. Yau JW, Rogers SL, Kawasaki R, et al. Global prevalence and major risk factors of diabetic retinopathy. Diabetes Care. 2012;35:556-564.

15. Kalk W, Huddle K, Raal F The age of onset and sex distribution of insulin-dependent diabetes mellitus in Africans in South Africa. Postgrad Med J. 1993;69:552-6.

16. Swai A, Lutale J, McLarty D Diabetes in tropical Africa: a prospective study, 1981-7. I. Characteristics of newly presenting patients in Dar es Salaam, Tanzania, 1981-7. BMJ. 1990;300:1103-6.

17. Motala AA, Pirie FJ, Gouws E, Amod A, Omar M Microvascular complications in South African patients with long-duration diabetes mellitus. S Afr Med J. 2001;91:987-92.

18. Omar M, Asmal A Patterns of diabetes mellitus in young Africans and Indians in Natal. Trop Geogr Med. 1984;36:133-8.

19. Glover SJ, Burgess PI, Cohen DB, et al. Prevalence of diabetic retinopathy, cataract and visual impairment in patients with diabetes in sub-SaharanAfrica. Br J Ophthal. 2012;96:156-61.

20. Jingi AM, Nansseu JRN, Noubiap JJN Diabetes and visual impairment in sub-Saharan Africa: evidence from Cameroon. J Diabetes Metab Disord. 2015;14:1.

21. Kalk W, Joannou J, Ntsepo S, Mahomed I, Mahanlal P, Becker P Ethnic differences in the clinical and laboratory associations with retinopathy in adult onset diabetes: studies in patients of African, European and Indian origins. J Intern Med. 1997;241:31-37.

22. Erasmus R, Alanamu R, Bojuwoye B, Oluboyo P, Arije A Diabetic retinopathy in Nigerians: relation to duration of diabetes, type of treatment and degree of control. East Afr Med J. 1989;66:248-54.

23. Rotimi C, Daniel H, Zhou J, et al. Prevalence and determinants of diabetic retinopathy and cataracts in West African type 2 diabetes patients. Ethn Dis. 2003;13:110-7. Suppl 2

24. Mbanya JCN, Motala AA, Sobngwi E, Assah FK, Enoru ST Diabetes in sub-saharan africa. Lancet. 2010;375:2254-66.

25. Tuei VC, Maiyoh GK, Ha CE Type 2 diabetes mellitus and obesity in sub-Saharan Africa. Diabetes Metab Rev. 2010;26:433-45. 